\section{A.4 OVEREXERTION RELATED AGE-SPECIFIC WMSDS CLAIMS AMONG CONSTRUCTION WORKERS IN OHIO, USA: 2007-2013}

${ }^{1}$ Harpriya Kaur*, ${ }^{2}$ Mike Lampl, ${ }^{1}$ James Grosch, ${ }^{1}$ Steven Wurzelbacher, ${ }^{1}$ Chih-Yu Tseng, ${ }^{1}$ Tim Bushnell, ${ }^{1}$ Juliann Scholl, ${ }^{1}$ Alysha Meyers, ${ }^{1}$ Bermang Ortiz. 'National Institute for Occupational Safety and Health/Centers for Disease Control and Prevention, Cincinnati, USA; ${ }^{2}$ Division of Safety and Hygiene, Pickerington, USA

\subsection{6/OEM-2019-EPI.113}

Background As the proportion of older workers in the U.S. increases, understanding the health and safety needs of an aging workforce is critical, especially in the hazardous and physically demanding construction industry. According to the Bureau of Labor Statistics (BLS), in 2016 the rate of workrelated musculoskeletal disorders (WMSDs) in construction was 32.7 per 10000 full-time equivalent workers, which was $11 \%$ higher than the rate for all industries combined. The objective of this study was to examine the rate and cost of WMSDs due to overexertion, the leading cause of WMSDs, among construction workers by age group in Ohio using workers' compensation claims.

Methods Overexertion related WMSDs allowed claims, submitted to Ohio Bureau of Worker's Compensation (OBWC) by workers in the construction industry for injuries occurring from 2007-2013 were analyzed to compute rates of allowed claims and claim costs by age group. The American Community Survey of the U.S. Census Bureau was used to determine the proportion of construction workers in each age group in Ohio. For this study, age was categorized as 14-24, 25-34, $35-44,45-54$ and $\geq 55$ years old.

Results There were 7434 overexertion related WMSD claims accepted by OBWC for construction workers who were injured due to overexertion in 2007-2013. Workers 35-44 years old experienced the highest claim rate of 7.28 per 1000 for WMSDs due to overexertion. However, the highest mean medical compensation cost for WMSD claims due to overexertion was for construction workers 55 years and older.

Conclusion Overexertion-related WMSD claims appear to rise and then fall with age $(\geq 55)$. There is a need to understand how aging interacts with WMSDs risk factors. Age-specific interventions to reduce WMSDs may help to retain older and skilled workers whose knowledge and experience might otherwise be lost when workers need to leave work because of debilitating WMSDs.

\section{A.5 OCCUPATIONAL DRIVING OF LIGHT VEHICLE FOR MAIL AND PARCEL DELIVERY AND RISK OF MUSCULOSKELETAL DISORDERS}

Anca Radauceanu*, Michel Grzebyk, Mathieu Dziurla, Jean-Jacques Atain-Kouadio, Stéphanie Boini. French Research and Safety Institute for the Prevention of Occupational Accidents and Diseases (INRS), Vandoeuvre-lès-Nancy, France

\subsection{6/OEM-2019-EPI.114}

Background Occupational light vehicle driving is becoming increasingly important in the parcel delivery/messaging sector faced with new consumer practices. Our objective was to analyze the effect of driving of light vehicle for the mail/parcel delivery on low back pain (LBP) and upper-extremity musculoskeletal disorders (UEMSDs) taking into account work organization. We also aimed to identify the protective factors from MSDs that could be implemented into this specific workplace.

Methods The study was carried out in 406 postal workers (306 with driving delivery activity, 100 with foot delivery/manual handling activities). Subjects completed a self-administrated questionnaire about personal characteristics and working conditions assessing occupational driving, physical constraints, psychosocial factors and work organization. Work organization was also assessed at the establishment level. MSDs were assessed by the Nordic Questionnaire, with some additional questions for LBP. For UEMSDs, a medical examination using a standardized clinical methodology of the European consensus was carried out. Statistical analysis was performed separately in men and women by multivariable logistic regression modeling for the UEMSDs and by item response theory approach for LBP.

Results Driving time and high perceived driving-related physical constraints are associated to LBP in men. Carrying loads $>3 \mathrm{Kg}$, awkward postures and high perceived physical demands related to parcel loading and delivery are associated with MSDs for both sexes. The main psychosocial risk factors are the lack of reward, being mobbed and the necessity of undertaking tasks that the worker disapproves. Protective factors are the use of vehicles fitted with automatic gearbox and taking breaks from work; at establishment level, drive training and use of supplementary staff during peak periods.

Conclusion The effect of driving of light vehicle on MSDs seems quite limited whereas physical and psychosocial constraints are clearly risk factors. Targeting work organization could protect postal workers with driving delivery activity from MSDs.

\section{A.6 OBJECTIVELY ASSESSED ARM ELEVATION AND THE COURSE OF NECK AND SHOULDER PAIN DURING A 2- YEAR FOLLOW-UP: A COMPOSITIONAL APPROACH}

Suzanne Merkus*, Lars-Kristian Lunde, Markus Koch, Stein Knardahl, Kaj Bo Veiersted. National Institute of Occupational Health, Oslo, Norway

\subsection{6/OEM-2019-EPI.115}

Purpose To use a compositional data analysis approach and objective exposure assessments to study the association between the duration of arm elevation and the course of neck and shoulder pain (NSP) during a 2-year follow-up in physically demanding occupations.

Methods Construction $(n=59)$ and healthcare $(n=59)$ employees wore accelerometers on the dominant upper-arm during a full working day at baseline. Objective assessments using accelerometers addresses biases found in previous studies that estimate duration of arm elevation with self-reports. At baseline and every 6 months for two years, participants reported on NSP (scale 0-3). Duration of arm elevation within predefined ranges $\left(<30^{\circ} ; 30-60^{\circ} ; \geq 60\right)$ formed the parts of the composition. Compositional data analysis is a new statistical analysis method within occupational health and it is the correct way of analysing data with a compositional nature. The associations between the relative importance of the duration within the levels of arm elevation and the course of NSP during the 2-year follow-up were estimated with compositional linear mixed models, adjusted for confounders.

Results In non-adjusted analyses, only duration arm elevation $<30^{\circ}$ was associated with NSP at baseline $(ß=0.37$; 
$\mathrm{p}=0.015)$. Duration arm elevation $<30^{\circ}$ had a tendency to be associated with an improvement in NSP over the 2-year follow-up $\left(<30^{\circ *}\right.$ time $\left.(ß=-0.07 ; \mathrm{p}=0.089)\right)$. Neither duration $30-$ $60^{\circ}$ nor $\geq 60$ were associated with the course of NSP during follow-up. After adjusting for confounders, none of the durations of arm elevation were associated with the course of NSP over the 2-year period $\left(<30^{\circ}\right.$ and NSP $(B=0.20 ; \mathrm{p}=0.126)$; $<30^{\circ}$ *time $(\beta=-0.06 ; \mathrm{p}=0.097)$ ).

Conclusion Among construction and healthcare personnel, duration of working in awkward arm elevation postures was not associated with the course of NSP over a 2-year period. Arm elevation alone, without considering force exertion, may not be sufficient to influence the course of NSP.

\section{Dermal Effects}

\section{B.1 WORKPLACE EXPOSURE ASSESSMENT (WEA), SKIN BARRIER FUNCTION, AND OCCURRENCE OF HAND ECZEMA AMONG WORKERS HANDLING DRILLING WASTE IN NORWAY}

${ }^{1}$ Jose Hernan Alfonso*, ${ }^{2}$ Raymond Olsen, ${ }^{2}$ Pål Graff, ${ }^{2}$ Shan Zienolddiny, ${ }^{2}$ Kristine Haugen Anmarkrud, ${ }^{2}$ Thea Haugesten Johansen, ${ }^{2}$ med Dag G Ellingsen. 'Dep. of Occupational Medicine and Epidemiology. National Institute of Occupational Health, Oslo, Norway; ${ }^{2}$ Dep. of Chemical and Biological Work Environment, National Institute of Occupational Health, Oslo, Norway

\subsection{6/OEM-2019-EPI.116}

Introduction Knowledge on skin exposure and the occurrence of hand eczema (HE) among workers handling drilling waste from oil and gas drilling is scarce.

$\mathbf{M}$ and $\mathbf{M}$ WEA included seven waste management plants. Samples of oil drilling waste were analysed with gas chromatography with flame ionization detection (GC-FID). Dry solids from thermal treatment of cuttings fluids were incubated in an artificial sweat solution and analysed with inductively coupled plasma mass spectrometry (ICP-MS). pH of dry solids in the sweat solution was measured with Panpeha ${ }^{\mathrm{TM}} \mathrm{pH}$ indicator strips.

Sixty-eight workers got an invitation to participate in a structured interview and skin examination. The Nordic Occupational Skin Questionnaire 2002 assessed the occurrence of skin problems and HE. Transepidermal water loss (TEWL) and hydration of the stratum corneum (SC) were measured with Tewameter 300 and Corneometer CM 825 (Courage and Khazaka Electronic GmbH).

Results WEA identified scenarios for potential skin exposure. The profile of hydrocarbons in oil-based drilling waste was similar among the different plants. The soluble fraction of dry solids in artificial sweat solution contained bioavailable metals such as Cr (from 22 to $210 \mathrm{ng} / \mathrm{g}$ ), Co (from 20 to $94 \mathrm{ng} / \mathrm{g}$ ), $\mathrm{Ni}$ (from 0,13 to $0,72 \mu \mathrm{g} / \mathrm{g}$ ). The $\mathrm{pH}$ ranged from 6.5 to 12.0.

The participation frequency was of 97\%. The one-year prevalence for $\mathrm{HE}$ and work-related $\mathrm{HE}$ was $30.3 \%$ and $24.2 \%$. Ninety-three percent of the workers reported glove use for two hours or more. TEWL values $>25 \mathrm{~g} / \mathrm{h} / \mathrm{m}^{2}$ on the dorsal side of the hands, indicating skin barrier disruption, were measured in $55 \%$ of the workers. TEWL and hydration of SC values were associated to the occurrence of $\mathrm{HE}$.
Conclusion Potential skin exposure to irritants, allergenic metals, skin occlusion from gloves, skin barrier disruption and high occurrence of HE among workers handling oil and drilling waste are of concern.

\section{B.2 DERMAL EXPOSURE TO SOLVENTS: A NEED FOR QUANTITATIVE ANALYSIS}

${ }^{1}$ Radu-Corneliu Duca*, ${ }^{2}$ Horatiu Moldovan, ${ }^{1}$ Matteo Creta, ${ }^{1}$ Katrien Poels, ${ }^{2}$ Septimiu Voidazan, 1,3'Lode Godderis, 'Jeroen Vanoirbeek. 'Environment and Health, KU Leuven (University of Leuven), Leuven, Belgium; ${ }^{2}$ Occupational Medicine Department, University of Medicine and Pharmacy of Tirgu-Mures, Tirgu-Mures, Romania; ${ }^{3} / d e w e$, External Service for Prevention and Protection at Work, Heverlee, Belgium

\subsection{6/OEM-2019-EPI.117}

For many years, airborne exposure was considered as the main work-related exposure and efforts have been made both on air monitoring and reduction of respiratory exposure. Nevertheless, recent studies have shown that preventive strategies with an exclusive focus on airborne exposures may falsely indicate a 'safe' environment. In 2014, WHO highlighted the importance of dermal exposure and its potential impact on human health. Moreover, it stipulated that the current technical and knowledge gaps related to the assessment of skin exposure have major lacunae.

In this context, there is an increased demand for standardized methods and tools for measuring and assessing skin exposure to hazardous agents.

We have developed an analytical method to simultaneously identify and quantify 195 volatile organic compounds (VOC) in dermal patches with activated charcoal cloth (ACC). Furthermore, we have done several field studies in different industrial settings, by the simultaneous assessment of dermal exposure using the ACC patches (on the hand, arm and neck), together with assessment of the respiratory exposure and determining the actual internal dose via urinary biomonitoring. Toluene, acetone and styrene exposure was found in a thermoplastic panel factory, styrene exposure in a composites body parts manufacturer, limonene and 1-methoxy-2-propanol exposure in a company that produces and prints plastic cartridges, and acetone and toluene in a pharmaceutical company. The results obtained from the quantitative ACC patches have been compared to the data obtained using Riskofderm for skin exposure, and the penetration through the skin was further estimated using IH-Skinperm and correlated with biomonitoring results.

Based on the analytical development and the results of the different field studies, we can conclude that ACC patches represent a suitable technique to evaluate the deposition of VOCs on the skin. We further believe that assessing dermal exposure to solvents using ACC patches can substantially improve occupational health programs.

\section{O5B.3 SKIN HEALTH IN CROATIAN HAIRDRESSING APPRENTICES AT THE BEGINNING OF VOCATIONAL EDUCATION: A NEW COHORT STUDY}

Zrinka Franic*, Zeljka Babic, Jelena Macan. Institute for Medical Research and Occupational Health, Zagreb, Croatia

10.1136/OEM-2019-EPI.118 